\title{
Psychiatrists on the General Medical Council: Elections 1999
}

The College will be publishing in the Psychiatric Bulletin the names of those psychiatrists who inform the College that they intend to stand for election to the General Medical Council (GMC) in 1999. Members who have agreed to stand for election should, therefore, contact the Secretary so that their names can be included in the printed list which will appear in the April Bulletin.

The following information describes the composition of the GMC and its election process.

The GMC has 104 members from three groups. These are elected and appointed doctors, as well as lay members nominated by the Privy Council. The majority of doctors (54) are elected and these are made up of 42 from England, seven for Scotland, three for Wales and two for Northern Ireland. There are 24 other doctors appointed by undergraduate and postgraduate bodies and finally 25 lay members. The four Chief Medical Officers (England, Wales, Scotland and Northern Ireland) attend ex officio and may take part in debates, but have no voting rights. Membership is up to the age of 70 when retirement is compulsory. Dr Sheila Mann is an appointed member representing the Colleges. Professor Andrew Sims and Dr Pearl Hettiaratchy are currently elected GMC members. There should be more psychiatrists on the GMC as they are currently under-represented.

Those who are considering standing for election should know what being an elected member entails. Successful elected members will start on 1 November 1999 for a five-year period. Any registered medical practitioner who has not reached the age of 70 is qualified to be nominated as a candidate and requires the nomination paper (obtainable from the GMC) to be signed by six registered medical practitioners, resident in the same constituency as themselves.
The single transferable vote is used so electors have to give an order of preference. The details on the ballot sheet include registered qualifications, date of birth and current principal appointment. Each candidate is asked to provide a brief summary about themselves and a photograph. A succinct self-report of about 100 words should make points that will encourage colleagues' support. This should include speciality, skills and areas of expertise. Those thinking of standing for election also should decide what they could bring to the GMC and its committees, particularly if they have been involved with medical education, ethics, standards, performance, health and conduct.

The GMC's functions are to protect patients and guide doctors. The Council was set up in 1858 when there were many charlatans and no register of trained doctors with medical qualifications. There were few standards for proper medical behaviour or criteria for the education and training of medical students. The GMC has come a long way since then, though there is still misunderstanding about its functions. It is not solely concerned with striking off erring doctors.

Psychiatrists should think seriously now about the next GMC election. Formal notice of the election will be given in the medical press on Friday 22 January 1999. The last date for the return of nomination papers will be Friday 19 February 1999. Voting will take place in May and the results will be known at the end of June. There is a need to encourage psychiatrists to stand for election in all GMC constituencies. Also, those already on the GMC will need to be re-elected.

Thomas Bewley, Consultant Psychiatrist, 4 Grosvenor Gardens Mews North, London SWIW OJP 